\title{
Carotid artery stenting in the context of endovascular treatment of acute ischemic stroke
}

\author{
Angioplastia com stent de carótida no contexto do tratamento endovascular do acidente \\ vascular cerebral isquêmico agudo
}

Adson F. de Lucena', Luís Henrique de Castro-Afonso', Lucas M. Monsignore', Guilherme S. Nakiri', Soraia R. C. Fábio², Octávio Pontes-Neto², Daniel Giansante Abud ${ }^{1}$

\begin{abstract}
Mechanical thrombectomy as an adjunctive to intravenous thrombolysis is now the standard treatment for acute ischemic stroke (AIS) due to large vessel occlusions. However, the best management of acute carotid tandem occlusions (CTO) remains controversial. Method: Twenty patients underwent endovascular treatment of acute CTO. The primary endpoint was the composite rate of complete or partial recanalization without a symptomatic intracranial hemorrhage $(\mathrm{SICH})$. Secondary endpoints were recanalization times, procedure times, and clinical outcomes at three months. Results: The primary endpoint was reached in 17 (85\%) patients. Recanalization rate was reached in 90\% of patients (19/20) and sICH rate was 5\% (1/20). At the 3 -month follow-up we obtained a mRS $\leq 2$ rate of $35 \%$ (7/20) and a mortality rate of $20 \%$ (4/20). Conclusion: Carotid angioplasty stenting and endovascular treatment of AIS due to CTO appears effective with an acceptable rate of $\mathrm{SICH}$.
\end{abstract}

Keywords: acute ischemic stroke, symptomatic carotid artery stenosis, carotid angioplasty stenting.

RESUMO

Trombectomia mecânica com stentrievers associada a trombólise endovenosa com rTPA é o tratamento padrão-ouro do acidente vascular cerebral isquêmico agudo (AVCi) devido à oclusões de grandes vasos. No entanto, a melhor estratégia terapêutica para oclusões carotídeas combinadas ainda permanece controversa. Método: Vinte paciente receberam tratamento endovascular. O desfecho primário foi a taxa de recanalização completa sem sangramento intracraniano sintomático. Os desfechos secundários foram os tempos de recanalização, duração dos procedimentos e desfechos clínicos em 3 meses. Resultados: 0 desfecho primário foi alcançado em 17 (85\%) pacientes. A taxa de recanalização foi de 90\% (19/20) e a taxa de HIS foi de $5 \%$ (1/20). Em três meses, foi obtido bom desfecho neurológico em 35\% (7/20) dos pacientes e a mortalidade foi de 20\% (4/20). Conclusão: A angioplastia com stent de carotída associada ao tratamento endovascular para oclusões combinadas agudas de carótida parece ser efetiva sem um aumento de HIS.

Palavras-chave: acidente vascular cerebral isquêmico agudo, estenose carotídea sintomática, angiolastia com stent de carótida.

Intravenous thrombolysis (IVT) with recombinant tissue plasminogen activator ( $\mathrm{r}$-tPA) is the standard treatment for acute ischemic stroke (AIS) within the first four and a half hours of symptom onset ${ }^{1}$, and five recent clinical trials demonstrated better clinical outcomes when mechanical thrombectomy with stentrievers were performed as an adjunctive treatment to IVT for patients presenting large vessel occlusions within the first six hours of symptom onset $t^{2,3,4,5}$. However, those trials lacked sufficient power to evaluate the clinical outcomes of patients presenting carotid tandem occlusions. Carotid tandem occlusions are defined as both extra-cranial occlusion or stenosis of the internal carotid artery (ICA) and downstream intracranial vessel occlusion, which comprises a subgroup of patients that usually present poor recanalization rates under IVT and poor clinical outcomes ${ }^{6}$. Despite of the lack of clinical data from randomized trials on the best management course of acute carotid tandem occlusions, a combined recanalization strategy by means of carotid artery stenting and mechanical thrombectomy has recently shown promising results $7,8,9,10,11,12,13,14,15,16,17,18,19,20,21,22,23,24,25$.

We aimed to assess the clinical and radiological data of patients who underwent carotid artery stenting (CAS) and

\footnotetext{
${ }^{1}$ Universidade de São Paulo, Faculdade de Medicina de Ribeirão Preto, Divisão de Neurorradiologia Intervencionista, Ribeirao Preto SP, Brazil;

${ }^{2}$ Universidade de São Paulo, Faculdade de Medicina de Ribeirão Preto, Divisão de Neurologia, Ribeirao Preto SP, Brazil.

Correspondence: Daniel Giansante Abud, Avenida Bandeirantes, 3900; 14048-090 Ribeirão Preto SP, Brasil; E-mail: dgabud@fmrp.usp.br

Conflict of interest: There is no conflict of interest to declare.

Support: Pontes-Neto FAPESP 2012/51725-2.

Received 01 June 2015; Received in final form 19 October 2015; Accepted 09 November 2015.
} 
endovascular treatment of acute ischemic stroke due to carotid tandem occlusions.

\section{METHOD}

\section{Study design, patients, and endpoints}

We retrospectively evaluated the clinical and radiological data of a consecutive series of patients who were treated for AIS due to carotid tandem occlusions by means of CAS and endovascular treatment of acute ischemic stroke from January 2009 to December 2014 by the stroke team of the Ribeirão Preto Medical School, University of São Paulo. The inclusion criteria to our study were endovascular treatment with carotid stent for acute ischemic stroke. The criteria for considering tandem occlusion in the current study was an extra-cranial occlusion or stenosis (> 50\%) of the internal carotid artery (ICA) and a downstream intracranial vessel occlusion visualized by digital subtracted angiography.

This study was approved by the ethics committee of our Institution, and the review board waived the need for written informed consent from the participants. The patients were selected for endovascular treatment according to our institution's acute stroke protocol for recanalization strategies, which has been previously published ${ }^{26}$.

The primary composite endpoint was the complete or partial recanalization rate immediately after endovascular procedure and absence of symptomatic intracranial hemorrhage (sICH) at 72 hours. The secondary endpoints were recanalization times, procedure duration, and clinical outcomes at three-month follow-up.

A total of 20 patients were included in the study, of which $12(60 \%)$ underwent intravenous r-tPA and endovascular treatment, and 8 (40\%) had endovascular treatment alone. Among the 8 patients who did not received intravenous r-tPA, 5 patients were admitted beyond 4.5 hours from symptoms onset, 2 patients were using anticoagulation medications, and 1 patient had a recent open surgery. Tables 1 and 2 summarize the study sample and individual patient baseline data, respectively.

Regarding the occlusion site, 14 patients (70\%) presented proximal internal carotid occlusions associated with additional intracranial occlusion and six patients (30\%) presented carotid stenosis (>50\%) and an intracranial occlusion (Table 2).

All patients were examined by independent certified vascular neurologists at hospital admission, who measured their neurological deficits using the National Institutes of Health Stroke Scale (NIHSS). Three brain CT scans were obtained; a first CT was done at admission, and a second and third brain CT scan was obtained within 24 hours and at 72 hours after treatment, respectively. We defined symptomatic intracranial hemorrhage according to the SITS-MOST definition: a
PH-2 (blood clot exceeding 30\% of the infarcted volume with significant space occupying effect) or subarachnoid hemorrhage on the post-treatment imaging scan leading to a decline in NIHSS of $\geq 4$ points or causing death (modified Rakin scale - mRS 6) within $36 \mathrm{~h}^{27}$.

The neurologic outcomes of patients were assessed using the mRS at three-month follow-up through electronic medical records or telephone conference. Time from symptom onset to recanalization and procedure duration were recorded. The procedure duration began with the groin puncture and ended at the instant of maximal recanalization. Recanalization was assessed using the thrombolysis in cerebral infarction score (TICI). As originally described, TICI categories span from no perfusion (grade 0) to complete per-

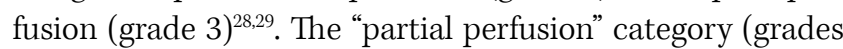
$1,2 \mathrm{a}$ and $2 \mathrm{~b}$ ) was used in this study accordingly to the modified version of the original TICI score ${ }^{30}$. In the modified version of TICI score the grade 1 was defined as antegrade reperfusion past the initial occlusion, but limited distal branch filling with little or slow distal reperfusion; grade $2 \mathrm{a}$ as an antegrade reperfusion of less than half of the occluded target artery previously ischemic territory (eg, in 1 major division of the MCA and its territory); and grade $2 \mathrm{~b}$ as an antegrade reperfusion of more than half of the previously occluded target artery ischemic territory (eg, in 2 major divisions of the MCA and their territories).

\section{Neurointerventional procedure}

For the endovascular treatment in general we performed local anesthesia with conscious sedation. Intubation of patients was performed whenever necessary (indications mainly included extreme patient agitation, neurologic deterioration, pulmonary or cardiac complications). All of the procedures were performed using femoral artery access. An

Table 1. Clinical characteristics of patients $(n=20)$.

\begin{tabular}{lc}
\hline Demographic and clinical data & \\
\hline Age: average in years ( \pm SD) & $67.1 \pm 11.4$ \\
Female & $6(30 \%)$ \\
Male & $14(70 \%)$ \\
NIHSS, Median (IQ) & $16(9.8 \%)$ \\
\hline ASPECTS score, Median (IQ) & $9(2.0 \%)$ \\
Aetiology of carotid lesion & \\
Dissection & $1(5 \%)$ \\
Atherosclerosis & $19(95 \%)$ \\
Site of intracranial occlusion & \\
Distal Segment ICA & $8(40 \%)$ \\
\hline MCA M1 & $10(50 \%)$ \\
MCA M2 & $1(5 \%)$ \\
MCA M4 & $1(5 \%)$ \\
Mean Recanalization time in minutes $( \pm$ SD) & $329 \pm 119.0$ \\
\hline Mean Procedure time in minutes $( \pm$ SD) & $89 \pm 46.9$ \\
\hline $\begin{array}{l}\text { NIHSS: National Institutes of Health Stroke Scale; MCA: middle cerebral } \\
\text { artery; M1, M2, M4: angiographyc segments of the middle cerebral artery; ICA: } \\
\text { internal carotid artery; SD: standard deviation. }\end{array}$
\end{tabular}




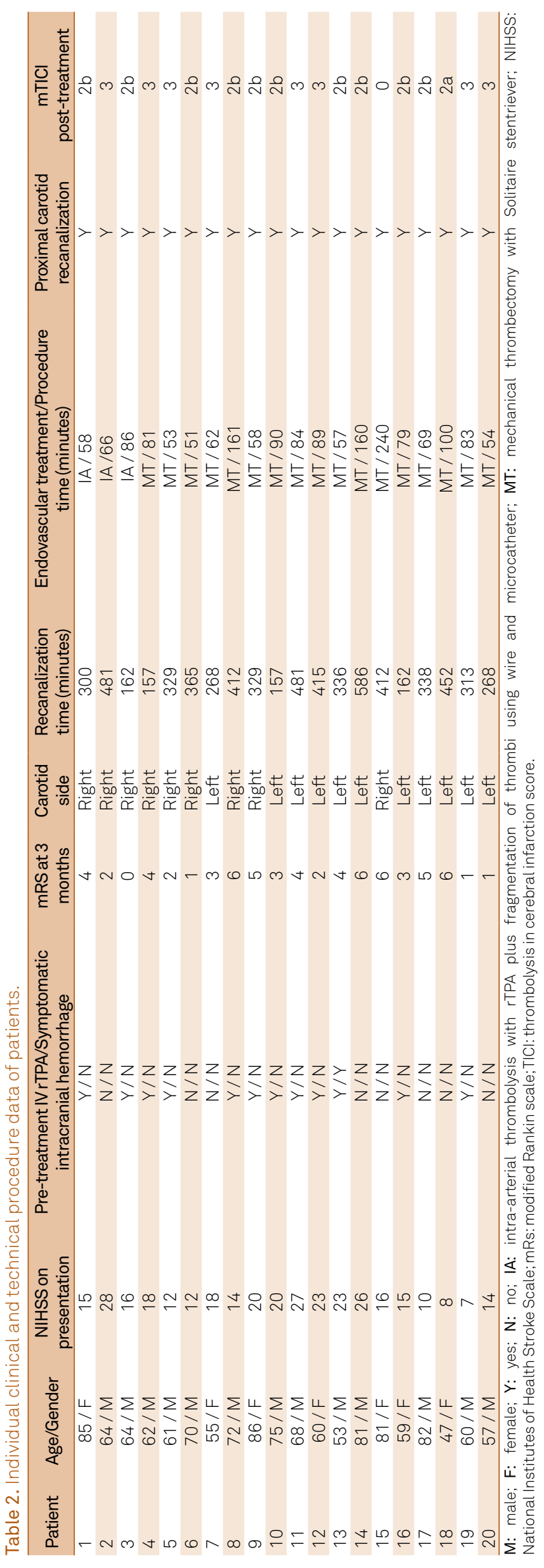

intravenous bolus of 5,000 IU of standard heparin was administered after the puncture if intravenous r-tPA was not previously infused. If r-tPA was infused prior to the endovascular procedure, no heparin was administered after the femoral puncture. The general antiplatelet regimen that was recommended was aspirin (300 $\mathrm{mg} /$ daily) and clopidogrel ( $75 \mathrm{mg} /$ daily) that was started at 24 hours after treatment and maintained during 3 months. After three months, we indicated only aspirin (100 mg/daily). For patients for whom an anticoagulant was indicated aiming secondary stroke prevention, like patients presenting atrial fibrillation, an association of aspirin ( $100 \mathrm{mg} /$ daily) and Warfarin sodium was indicated.

A 7-Fr guiding catheter (Guider Softip; Boston Scientific, Natick, MA) or a 6-Fr guiding catheter (Neuron; Penumbra, Alameda, CA) was introduced through a femoral sheath into the ICA. Carotid artery stenting was performed using a Wallstent (Boston Scientific, Natick, MA, USA) and a 5.5 or $6.0 \times 20 \mathrm{~mm}, 153 \mathrm{~cm}$, Monorail postdilatation balloon (Boston Scientific, Maple Grove, MN). After stenting, if a thrombus was still occluding cervical ICA, than we performed a manual thrombus aspiration across cervical internal carotid using a $60 \mathrm{cc}$ syringe connected through the guiding catheter. After that, for recanalization of intracranial artery we performed intra-arterial infusion of rTPA or mechanical thrombectomy using the Solitaire-FR device (Microvention-Covidien, Irvine, CA). Successful recanalization was defined as a TICI score of 3 or $2 \mathrm{~b}$ in all of the treatable vessels. If the treatable vessel was not opened to a minimum of TICI $2 \mathrm{~b}$ after a maximum of five passes of the thrombectomy device, the treatment was considered a failure ${ }^{26}$.

\section{Statistical analysis}

Categorical variables were presented as numbers and percentages. Continuous variables were presented as mean (range, \pm standard deviation (SD)) or median and interquartile ranges.

\section{RESULTS}

Among all cases reported in this series, carotid angioplasty stenting was performed for all patients. Three patients (15\%) received intra-arterial r-tPA for recanalization of intracranial artery right after carotid stent placement, because these three cases were treated before stentriever become available at our institution. After that, all cases were performed using a stentriever for recanalization of intracranial vessels.

The primary endpoint (i.e., complete or partial recanalization of the intracranial occlusion graded and no sICH) was achieved in 17 patients (85\%). The recanalization rate (TICI $2 \mathrm{~b}$ or 3 ) was achieved in 18 patients $(90 \%)$, whereas a sICH was observed in one patient (5\%). 
The secondary endpoints were a mortality rate of $20 \%$ (4 patients) at three-month follow-up. One patient who had no recanalization (TICI score $=0$ ) died after three days because of a brain infarction edema, two patients died because of systemic infections, and one died because of a refractory cardiac arrhythmia. At three months, 35\% $(7 / 20)$ of the patients had mRS score $\leq 2$. The mean recanalization time was $336 \pm 119.7$ (SD) minutes (ranging from 157 to 586 minutes) and the mean procedure duration was $89 \pm 46.9$ (SD) minutes (ranging from 51 to 240 minutes). We had no complications related to the anesthesia, and no procedural related complications like vessel ruptures, arterial dissections or inadvertent Solitaire (Microvention-Covidien) detachment.

Figures 1 and 2 illustrate two successful endovascular procedures.

\section{DISCUSSION}

Carotid atherosclerotic stenosis is associated with approximately $15-20 \%$ of all ischemic strokes. Acute carotid tandem occlusions are a relatively common presentation of AIS; approximately $25 \%$ of patients with middle cerebral artery (MCA) occlusion will have a concomitant ICA occlusion, and $50 \%$ of patients with an ICA occlusion will have a proximal MCA occlusion. Acute carotid tandem occlusions have been reported to have low recanalization rates and poor outcomes even after IVT ${ }^{7}$.

Recent randomized trials represent a landmark for endovascular treatment of AIS due to large vessel occlusions ${ }^{2,3,4,5}$. Despite the fact that patients presenting acute carotid occlusions have large vessel occlusions and would thus probably benefit of the endovascular approach, recent randomized trials were not designed and powered to assess the outcomes of this specific subgroup of patients.
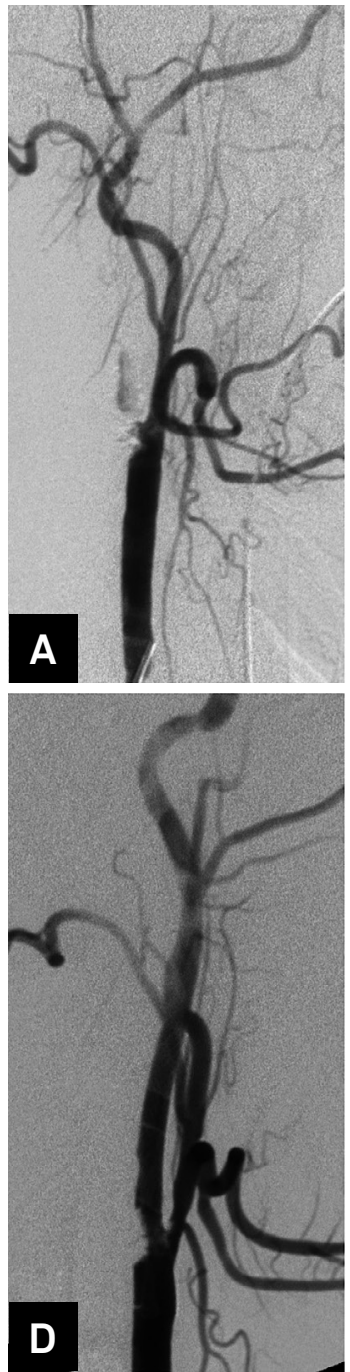
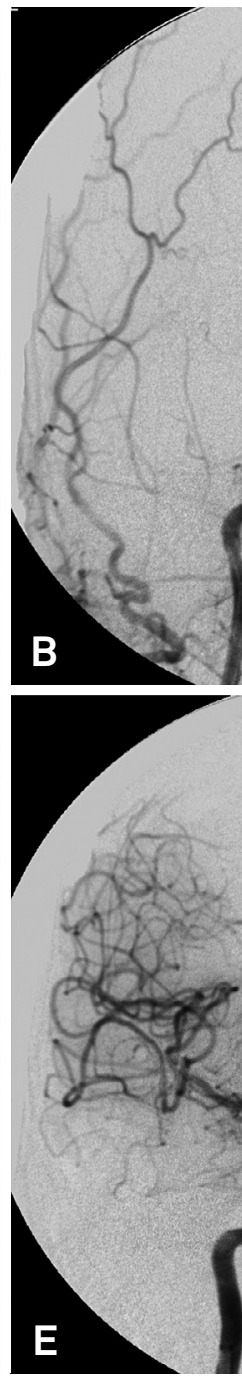
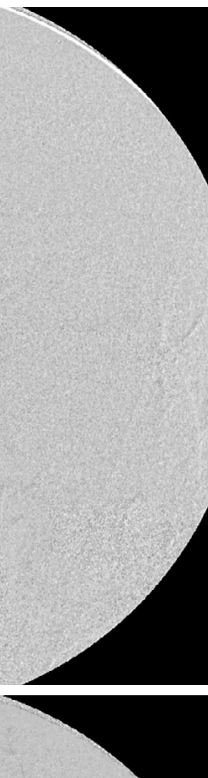
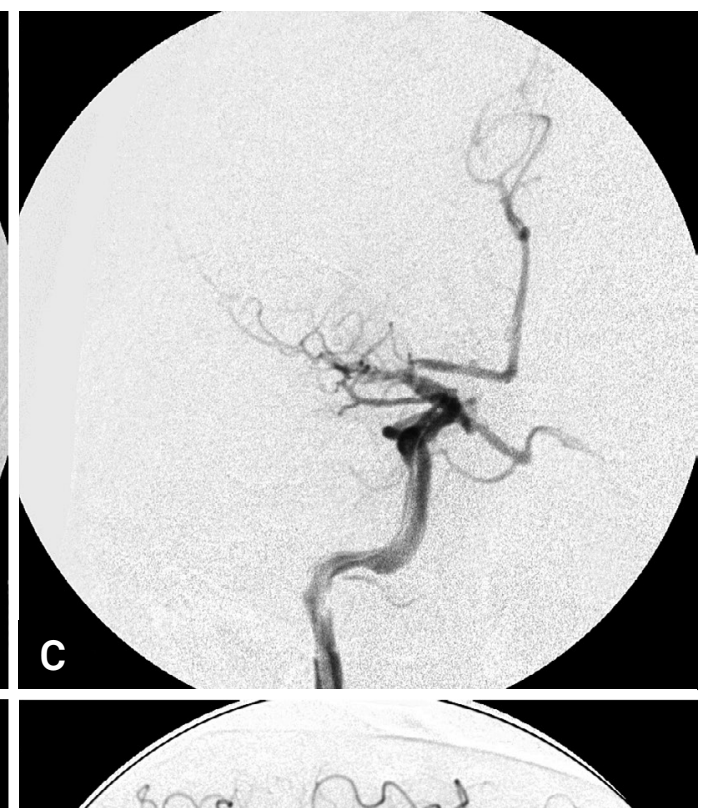

Figure 1. Patient 4. (A) Digital subtraction angiography (DSA) of the right common carotid artery (RCCA) arterial phase oblique view, shows an occlusion of the origin of right internal carotid artery (RICA); (D) DSA of the RCCA immediately after carotid stenting; (B) DSA of the RICA arterial phase, frontal view, performed after stenting shows a distal occlusion of the RICA; (C) DSA of the RICA arterial phase, right oblique view, shows partial recanalization after first Stentriever passage; (E, F) DSA of the RICA arterial phases, frontal view (E) and lateral view (F) show complete recanalization of the right carotid territory. 

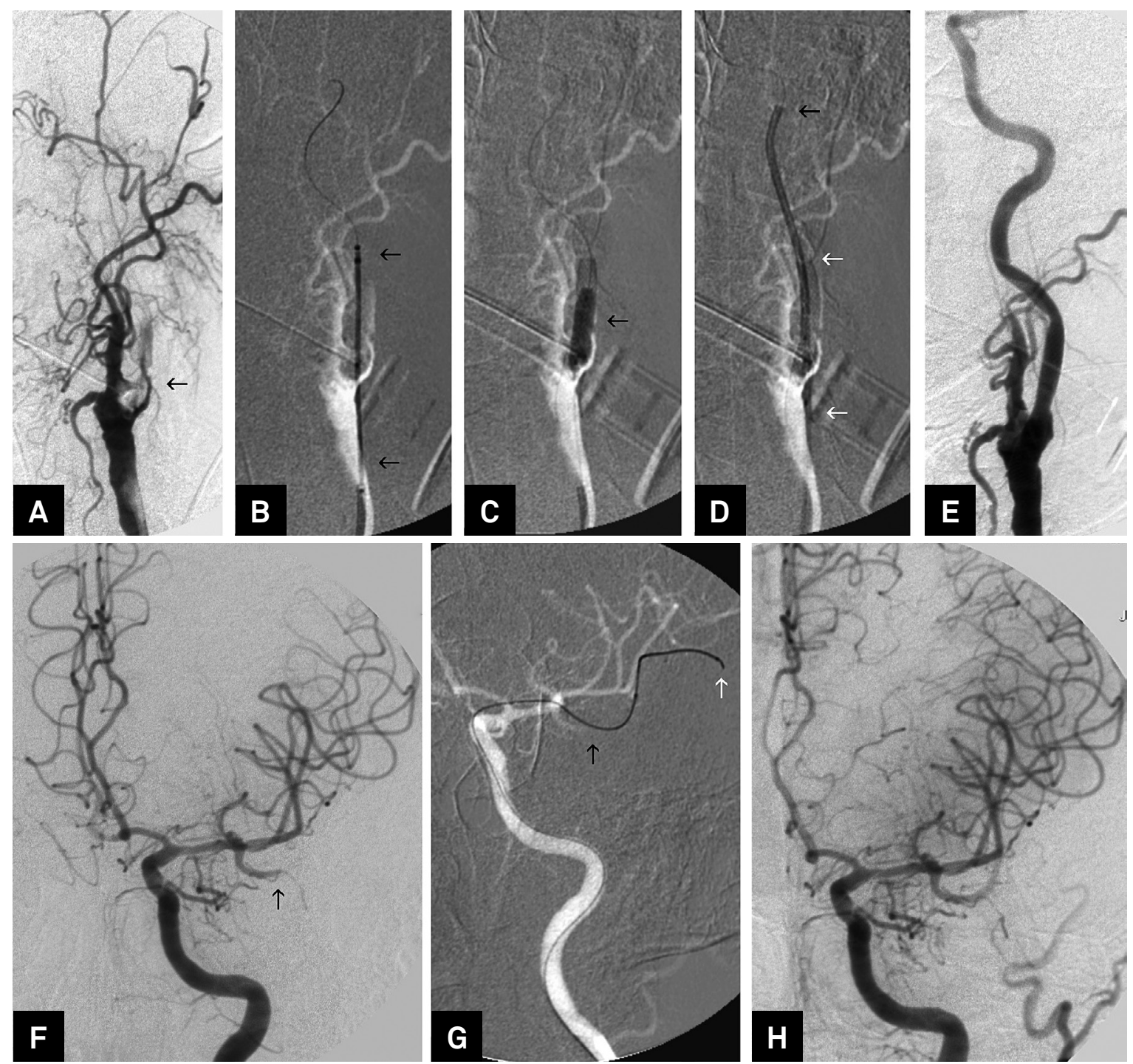

Figure 2. Patient 10. (A) Digital subtraction angiography (DSA) of the left common carotid artery (LCCA) arterial phase, oblique view, shows a proximal occlusion of the LICA (black arrow). (B, C, D) Road map of LCCA oblique view, shows (B) carotid Wallstent crossing LICA occlusion, (C) balloon angioplasty performed into the Wallstent, (D) and a 7F guiding catheter in the LICA for thrombus aspiration maneuver; (E) DSA of the LCCA arterial phase, oblique view, shows cervical left carotids completely opened; (F) DSA of the LICA, arterial phase, frontal view, shows a proximal occlusion of M2 segment of left middle cerebral artery (LMCA) (black arrow); (G) Road map of the LICA, frontal view, shows the distal tip of the microcatheter and microwire (white arrow) crossing the occluded branch of the LMCA for mechanical thrombectomy with stentriever (black arrow); (H) DSA of the LCCA, arterial phase, frontal view, performed after procedure shows partial recanalization of the LMCA (TICI $2 \mathrm{~b}$ ).

This study showed a primary endpoint of recanalization without a sICH in $85 \%$ of patients $(17 / 20)$. Our results were in accordance with results of previous similar studies (Table 3) $7,8,9,10,11,12,13,14,15,16,17,18,19,20,21,22,23,24,25$. Furthermore, this study showed rates of recanalization, sICH, and mortality that were similar to those found in recent randomized trials on thrombectomy for acute stroke $e^{2,3,4,5}$. Although implanting a carotid stent in the setting of AIS may increase the risks of in-stent thrombosis or intracranial hemorrhage because of the double anti-platelet regime, we had no cases of acute in-stent thrombosis and only one case $(5 \%)$ of sICH. In addition, mortality rate of $20 \%$ and the good neurologic outcome of $35 \%$ at 3 months were in accordance with previous similar studies and recent trials (Table 3 ).
Regarding recanalization and procedure duration, we achieved an average recanalization and procedure duration times of 336 minutes (5.6 hours) and 89 minutes (1.5 hour), respectively. These times were longer than the times usually obtained with mechanical thrombectomy alone. This finding may be explained by the two-in-one characteristic of the procedure, which is compounded by a carotid artery stenting and a mechanical thrombectomy.

Regarding the procedure technique, the best recanalization strategy for carotid tandem occlusions remains controversial. Some authors have reported a cerebral artery recanalization first, by passing cervical carotid occlusion or through one of the communicating arteries at the level of the circle of Willis ${ }^{30}$. On contrary, we routinely indicated a 
Table 3. An overview of the reported studies on CAS in acute cervical ICA occlusion.

\begin{tabular}{|c|c|c|c|c|c|c|c|c|}
\hline Author - Year & Sample & $\begin{array}{l}\text { Mean NIHSS } \\
\text { baseline }\end{array}$ & $\begin{array}{c}\mathrm{mTICl} 2 \mathrm{~b}, 3 \\
\mathrm{n}(\%)\end{array}$ & $\begin{array}{l}\text { Procedure } \\
\text { time (min) }\end{array}$ & $\begin{array}{c}\text { Mean recanalization } \\
\text { time (min) }\end{array}$ & $\begin{array}{l}\mathrm{sICH} \\
\mathrm{n}(\%)\end{array}$ & $\begin{array}{c}\mathrm{mRS} \leq 2 \\
3 \text { months } \mathrm{n}(\%)\end{array}$ & $\begin{array}{c}\text { Mortality } \\
\mathrm{n}(\%)\end{array}$ \\
\hline Imai et al. $2005^{13}$ & 17 & 12 & $17(100)$ & NR & NR & $1(6)$ & $11(64.7)$ & $1(6)$ \\
\hline Dabitz et al. $2007^{14}$ & 10 & 21 & $7(70)$ & NR & NR & $0(0)$ & $5(50)$ & $1(10)$ \\
\hline Heck et al. $2014^{23}$ & 23 & 17 & $21(91)$ & NR & NR & $5(22)$ & $12(52)$ & $9(39)$ \\
\hline Stampfl et al. $2014^{25}$ & 24 & 18 & $15(62.5)$ & 89.8 & NR & $4(16.6)$ & $7(29.2)$ & $4(16.6)$ \\
\hline Dababneh et al. $2014^{20}$ & 7 & 15 & $6(85)$ & NR & NR & NR & $4(57.1)$ & NR \\
\hline Kappelhof et al. $2014^{* 7}$ & 462 & 15 & 384 (83) & NR & NR & $41(8)$ & $121(26.2)$ & $161(34)$ \\
\hline Spiotta et al. $2014^{11}$ & 16 & 13.1 & $16(100)$ & 86 & NR & NR & $8(50)$ & $3(18.75)$ \\
\hline Maurer et al. $2014^{18}$ & 43 & 13.6 & $33(76.7)$ & NR & $N R$ & NR & $14(32.6)$ & NR \\
\hline Choi et al. $2014^{19}$ & 17 & 15.1 & $10(58.8)$ & NR & 277 & $2(11.8)$ & $9(52.9)$ & $3(17.6)$ \\
\hline Lockau et al. $2014^{24}$ & 37 & 17 & $27(73)$ & 73.5 & NR & $4(10.8)$ & $17(45.9)$ & $7(18.9)$ \\
\hline Son et al. $2015^{17}$ & 22 & 12.55 & $19(86.3)$ & 61 & NR & NR & $20(90)$ & $2(9)$ \\
\hline Yoon et al. $2015^{22}$ & 47 & 13.9 & $37(78.7)$ & 51 & 286 & $4(8.5)$ & $26(55.3)$ & $3(6.4)$ \\
\hline Puri et al. $2015^{22}$ & 23 & 18 & $17(74)$ & 35 & NR & $2(8.6)$ & $13(56.5)$ & $4(17.4)$ \\
\hline Lucena et al. 2015 & 20 & 17 & $18(90)$ & 89 & 336 & $1(5)$ & $7 / 20(35)$ & $4(20)$ \\
\hline Total (mean) & 773 & 16 & $623(80)$ & 69.3 & 299.6 & $65(8)$ & 267 (34.5) & $202(26)$ \\
\hline
\end{tabular}

NIHSS: National Institutes of Health Stroke Scale; CAS: carotid angioplasty stenting; ICA: internal carotid artery; NR: Not reported; TICl: thrombolysis in cerebral infarction score; mRs: modified Rankin scale.

proximal to distal approach using CAS and after a cerebral artery recanalization, because of the following reasons. First, a systematic review of observational studies suggested that CAS and mechanical thrombectomy may be superior to other recanalization strategies in the setting of carotid tandem occlusions $^{8}$. Second, CAS prevents the risk of acute proximal or distal artery reoclusions or recurrent cerebral embolism. Third, mechanic thrombectomy requires positioning a guiding-catheter into the internal carotid artery distal to the proximal carotid lesion. Therefore, CAS using a close-cell stent allows the guiding catheter to safely cross the proximal carotid lesion thorough the struts of the stent allowing for intracranial clot removal ${ }^{23}$. Fourth, recanalization of proximal carotid lesion may have advantages of improve collateral flow to the ischemic tissue, improve local perfusion pressure and delivers fresh blood to the intracranial occlusion site to facilitate endogenous thrombolysis, which may lead to immediate recanalization or to delayed recanalization even in the case of failed distal mechanic thrombectomy.
The results obtained in the present study were consistent with results of previous similar non-randomized studies that showed good outcomes with CAS and mechanical thrombectomy to treat patients presenting carotid occlusions. Although the studies reviewed are in most observational, which may have selection bias, the main results seem to be reproducible across studies (Table 3). Therefore, a pooled analysis of randomized trials to assess the best revascularization strategy for carotid tandem occlusions appear to be justified. In addition, the best antiplatelet and anticoagulation regimens, an ideal stent design and the best procedure protocol for each carotid lesion etiology need to be clarified.

The limitations of this study were the retrospective design, the small size and single-center sample and the lack of a control group.

In conclusion, a revascularization strategy with carotid angioplasty stenting and endovascular treatment of acute ischemic stroke due to carotid tandem occlusions appears effective without an increase of sICH.

\section{References}

1. Hacke W, Kaste M, Bluhmki E, Brozman M, Dávalos A, Guidetti $D$ et al. Thrombolysis with alteplase 3 to 4.5 hours after acute ischemic stroke. N Engl J Med. 2008;359(13):1317-29. doi:10.1056/NEJMoa0804656

2. Goyal M, Demchuk AM, Menon BK, Eesa M, Rempel JL, Thornton $J$ et al. Randomized assessment of rapid endovascular treatment of ischemic stroke. N Engl J Med. 2015;372(11):1019-30. doi:10.1056/NEJMoa1414905

3. Berkhemer OA, Fransen PS, Beumer D, Berg LA, Lingsma HF, Yoo AJ et al. A randomized trial of intraarterial treatment for acute ischemic stroke. N Engl J Med. 2015;372(1):11-20. doi:10.1056/NEJMoa1411587
4. Saver JL, Goyal M, Bonafe A, Diener HC, Levy El, Pereira VM, et al. Stentretriever thrombectomy after intravenous t-PA vs. t-PA Alone in Stroke. N Engl J Med. 2015;372(24):2285-95. doi:10.1056/NEJMoa1415061

5. Jovin TG, Chamorro A, Cobo E, Miquel MA, Molina CA, Rovira A et al. Thrombectomy within 8 hours after symptom onset in ischemic stroke. N Engl J Med. 2015;372(24):2296-306. doi:10.1056/NEJMoa1503780

6. Rubiera M, Ribo M, Delgado-Mederos R, Santamarina E, Delgado P, Montaner J et al. Tandem internal carotid artery/middle cerebral artery occlusion: an independent predictor of poor outcome after systemic thrombolysis. Stroke. 2006;37(9):2301-5. doi:10.1161/01.STR.0000237070.80133.1d 
Kappelhof M, Marquering HA, Berkhemer OA, Majoie CB. Intraarterial treatment of patients with acute ischemic stroke and internal carotid artery occlusion: a literature review.J Neurointerv Surg. 2015;7(1):8-15. doi:10.1136/neurintsurg-2013-011004

8. Fischer U, Mono ML, Schroth G, Jung S, Mordasini P, El-Koussy $M$ et al. Endovascular therapy in 201 patients with acute symptomatic occlusion of the internal carotid artery. Eur $\mathrm{J}$ Neurol. 2013;20(7):1017-24. doi:10.1111/ene.12094

9. Ratanaprasatporn L, Grossberg JA, Spader HS, Jayaraman MV. Endovascular treatment of acute carotid occlusion. Clin Neurol Neurosurg. 2013;115(12):2521-3. doi:10.1016/j.clineuro.2013.10.008

10. Mpotsaris A, Bussmeyer M, Buchner H, Weber W. Clinical outcome of neurointerventional emergency treatment of extra or intracranial tandem occlusions in acute major stroke: antegrade approach with wallstent and solitaire stent retriever. Clin Neuroradiol. 2013;23(3):207-15. doi:10.1007/s00062-013-0197-y

11. Spiotta AM, Lena J, Vargas J, Hawk H, Turner RD, Chaudry MI et al. Proximal to distal approach in the treatment of tandem occlusions causing an acute stroke. J Neurointerv Surg. 2015;7(3):164-9. doi:10.1136/neurintsurg-2013-011040

12. Qureshi Al. Endovascular revascularization of symptomatic acute extracranial internal carotid artery occlusion. Stroke. 2005;36(11):2335-6. doi:10.1161/01.STR.0000185930.45475.05

13. Imai K, Mori T, Izumoto H, Watanabe M, Majima K. Emergency carotid artery stent placement in patients with acute ischemic stroke. AJNR Am J Neuroradiol. 2005;26(5):1249-58.

14. Dabitz R, Triebe S, Leppmeier U, Ochs G, Vorwerk D. Percutaneous recanalization of acute internal carotid artery occlusions in patients with severe stroke. Cardiovasc Intervent Radiol. 2007;30(1):34-41. doi:10.1007/s00270-005-0286-7

15. Seet RS, Wijdicks EM, Rabinstein AA. Stroke from acute cervical internal carotid artery occlusion: treatment results and predictors of outcome. Arch Neurol. 2012;69(12):1615-20. doi:10.1001/archneurol.2012.2569

16. Cohen JE, Gomori JM, Rajz G, Itshayek E, Eichel R, Leker RR. Extracranial carotid artery stenting followed by intracranial stent-based thrombectomy for acute tandem occlusive disease. J Neurointerv Surg. 2015;7(6):412-7. doi:10.1136/neurintsurg-2014-011175

17. Son S, Choi DS, Oh MK, Kim SK, Kang H, Park KJ et al. Emergency carotid artery stenting in patients with acute ischemic stroke due to occlusion or stenosis of the proximal internal carotid artery: a single-center experience. J Neurointerv Surg. 2015;7(4):238-44. doi:10.1136/neurintsurg-2014-011141

18. Maurer CJ, Joachimski F, Berlis A. Two in one: endovascular treatment of acute tandem occlusions in the anterior circulation. Clin Neuroradiol. 2014 Jul 3. [Epub ahead of print]. doi:10.1007/s00062-014-0318-2

19. Choi JY, Lee JI, Lee TH, Sung SM, Cho HJ, Ko JK. Emergent recanalization with stenting for acute stroke due to athero-thrombotic occlusion of the cervical internal carotid artery: a single center experience. J Korean Neurosurg Soc. 2014;55(6):313-20. doi:10.3340/jkns.2014.55.6.313

20. Dababneh H, Bashir A, Hussain M, Guerrero WR, Morgan W, Khanna AY et al. Endovascular treatment of tandem internal carotid and middle cerebral artery occlusions. J Vasc Interv Neurol. $2014 ; 7(4): 26-31$.

21. Puri AS, Kühn AL, Kwon HJ, Khan M, Hou SY, Lin E et al. Endovascular treatment of tandem vascular occlusions in acute ischemic stroke. J Neurointerv Surg. 2015;7(3):158-63. doi:10.1136/neurintsurg-2013-011010

22. Yoon W, Kim BM, Kim DJ, Kim DI, Kim SK. Outcomes and prognostic factors after emergent carotid artery stenting for hyperacute stroke within 6 hours of symptom onset. Neurosurgery. 2015;76(3):321-9. doi:10.1227/NEU.0000000000000610

23. Heck DV, Brown MD. Carotid stenting and intracranial thrombectomy for treatment of acute stroke due to tandem occlusions with aggressive antiplatelet therapy may be associated with a high incidence of intracranial hemorrhage. J Neurointerv Surg. 2015;7(3):170-5. doi:10.1136/neurintsurg-2014-011224

24. Lockau H, Liebig T, Henning T, Neuschmelting V, Stetefeld H, Kabbasch $\mathrm{C}$ et al. Mechanical thrombectomy in tandem occlusion: procedural considerations and clinical results. Neuroradiology. 2015;57(6):589-98. doi:10.1007/s00234-014-1465-5

25. Stampfl S, Ringleb PA, Möhlenbruch M, Hametner C, Herweh C, Pham $\mathrm{M}$ et al. Emergency cervical internal carotid artery stenting in combination with intracranial thrombectomy in acute stroke. AJNR Am J Neuroradiol. 2014;35(4):741-6. doi:10.3174/ajnr.A3763

26. Castro-Afonso LH, Abud TG, Pontes-Neto OM, Monsignore LM, Nakiri GS, Cougo-Pinto PT et al. Mechanical thrombectomy with solitaire stent retrieval for acute ischemic stroke in a Brazilian population. Clinics (Sao Paulo). 2012;67(12):1379-86. doi:10.6061/clinics/2012(12)06

27. Wahlgren N, Ahmed N, Dávalos A, Ford GA, Grond M, Hacke $W$ et al. Thrombolysis with alteplase for acute ischaemic stroke in the Safe Implementation of Thrombolysis in StrokeMonitoring Study (SITS-MOST): an observational study. Lancet. 2007;369(9558):275-82. doi:10.1016/S0140-6736(07)60149-4

28. Higashida RT, Furlan AJ, Roberts H, Tomsick T, Connors B, Barr J et al. Trial design and reporting standards for intra-arterial cerebral thrombolysis for acute ischemic stroke. Stroke. 2003;34(8):e109-37. doi:10.1161/01.STR.0000082721.62796.09

29. Zaidat OO, Yoo AJ, Khatri P, Tomsick TA, Kummer R, Saver JL. Recommendations on angiographic revascularization grading standards for acute ischemic stroke: a consensus statement. Stroke. 2013;44(9):2650-63. doi:10.1161/STROKEAHA.113.001972

30. Kim DJ, Kim DI, Byun JS, Jung JY, Suh SH, Kim EY et al. Intraarterial thrombolytic therapy for hyperacute ischemic stroke caused by tandem occlusion. Cerebrovasc Dis. 2008;26(2):184-9. doi:10.1159/000145326 